\title{
Effect of Sintering Temperature on Property of Low-Density Ceramic Proppant Adding Coal Gangue
}

\author{
Jianying HAO ${ }^{1}$, Huilan HAO ${ }^{1}$, Yunfeng GAO ${ }^{1}$, Xianjun $\mathrm{LI}^{2}$, Mei QIN ${ }^{1}$, Kaiyue WANG ${ }^{1}$ \\ ${ }^{1}$ Institute of Materials Science and Engineering, Taiyuan University of Science and Technology, Taiyuan 030024, Shanxi, \\ China \\ ${ }^{2}$ Department of Civil Engineering, Shanxi University, Taiyuan 030013, Shanxi, China \\ crossref http://dx.doi.org/10.5755/j01.ms.26.1.19376
}

Received 27 October 2017; accepted 16 October 2018

\begin{abstract}
Calcined flint clay ( $45.6 \mathrm{wt} . \% \mathrm{Al}_{2} \mathrm{O}_{3}$ ) and solid waste coal gangue were used to prepare low-density ceramic proppant by solid state sintering method. The density and breakage ratio of the ceramic proppant were systematically investigated as a function of sintering temperature. The morphology and phase composition of the ceramic proppant were examined by scanning electron microscopy (SEM) and X-ray diffraction (XRD). The results show that the ceramic proppant is composed of rod-like mullite and granular cristobalite. Bulk density and apparent density of the proppant first rise and then slightly decrease with increasing the sintering temperature, while breakage ratios under $35 \mathrm{MPa}$ and $52 \mathrm{MPa}$ pressure gradually decrease and then increase. As the sintering temperature increases up to $1400{ }^{\circ} \mathrm{C}$, the ceramic proppant shows denser microstructure. The proppant sintered at $1400{ }^{\circ} \mathrm{C}$ have the best performance with $1.27 \mathrm{~g} / \mathrm{cm}^{3}$ of bulk density, $2.79 \mathrm{~g} / \mathrm{cm}^{3}$ of apparent density, $3.27 \%$ of breakage ratio under $35 \mathrm{MPa}$ closed pressure and $8.36 \%$ of breakage ratio under $52 \mathrm{MPa}$ closed pressure, which conform to the requirement of low-density ceramic proppant. The addition of solid waste can greatly reduce the preparation cost of the ceramic proppant.

Keywords: ceramic proppant, low-density, coal gangue, sintering.
\end{abstract}

\section{INTRODUCTION}

Oil fracturing proppant, used to "prop open" rock cracks, is key material in the exploration of oil and gas deep wells, and can increase the output of natural oil and gas wells [1]. Generally, the proppant with different strength and performance need to be developed according to the difference of oil and gas field. Now, quartz sand and ceramic proppant are more widely used in the hydraulic fracturing [2]. Since Stanolind Oil conducted the first experimental fracturing in the Hugoton field utilizing sand from the Arkansas River in 1947, sand has remained the most commonly used proppant for hydraulic fracturing process because of economic advantages [3]. However, the strength of quartz sand is insufficient for the long-term use of underground wells and quartz sand has poor sphericity [4]. Compared to quartz sand, ceramic proppant has more uniform in size and shape, and has higher sphericity and roundness to yield higher porosity and permeability of the proppant bed. Furthermore, ceramic proppant has superior performances, especially in terms of crush resistance [5].

Ceramic proppant can be further divided into three broad classifications based on its density: low-density ceramic, intermediate-density ceramic and high-density ceramic [6]. Low-density ceramic proppant is easy to pump and not easy to precipitate, and can reduce the viscosity requirements of the hydraulic fracturing fluid, reduce the damage to the pump, and effectively reduce the difficulty of construction and the cost of exploitation. Therefore, the ideal fracturing material should be lowdensity high-strength ceramic proppant [7].
The proppant density is typically governed by the percentage of alumina in the pellet, and, when the ceramic proppant is made properly, the alumina content will be proportional to the pellet strength [8]. High density of ceramic proppant currently used mainly results from the raw material of high-alumina bauxite [2]. Bauxite ore also makes the preparation cost of the ceramic proppant increase. Flint clay is also a natural ore containing $\mathrm{Al}_{2} \mathrm{O}_{3}$ and $\mathrm{SiO}_{2}$ and its $\mathrm{Al}_{2} \mathrm{O}_{3}$ content is much lower than that of bauxite. But $\mathrm{Al}_{2} \mathrm{O}_{3}$ content can increase after flint clay is calcined. Flint clay ore is rich in China.

Coal gangue is a hazardous by-product of coal mining industry and its average production is about $10-15 \%$ of raw coal production [9]. Efficient disposal of coal gangue is a worldwide problem owing to its massive accumulation and harmful effects on the environment [10]. Statistics show that approximately 3000 hills of coal gangue exist in China, the stockpile of coal gangue has reached 4.6-5.0 billion tons, and 0.2 billion tons of coal gangue is produced annually [11]. The huge amount of reserve is also a most important economic concern owing to the low utilization. Therefore the utilization of coal gangue has attracted extensive interests in recent years [12]. Efforts have been made to use coal gangue for different purposes. For example, coal gangue has been used in the manufacture of building products (pottery, cement, etc.) and refractories (mullite, SiC, etc.) [13]

Coal gangue has various chemical and mineral compositions and generally contains certain content of $\mathrm{SiO}_{2}$ and $\mathrm{Al}_{2} \mathrm{O}_{3}$, [14] which are necessary ingredients for preparing ceramic proppant. Other components in coal

\footnotetext{
* Corresponding author. Tel.: +86-351-2306774.

E-mail address: jyty2280@163.com (J. Hao)
} 
gangue can help to decrease the sintering temperature. Therefore, cheap flint clay and solid waste coal gangue can replace bauxite as raw materials of ceramic proppant.

In this research, low-cost low-density ceramic proppant was successfully prepared by raw materials of calcined flint clay partially replaced by coal gangue. Furthermore, the dependence of phase evolution, microstructure, bulk density, apparent density and breakage ratio on sintering temperature was thoroughly investigated.

\section{EXPERIMENTAL DETAILS}

Natural flint clay and solid waste coal gangue (Shanxi Yangquan, China) were used as raw materials. In order to ensure the alumina content in flint clay, flint clay was calcined at $1200{ }^{\circ} \mathrm{C}$ for $1 \mathrm{~h}$ using a muffle furnace. The chemical composition of the calcined flint clay was measured according to the Chinese Nonferrous Metals Industry Standard (YS/T 575-2007) and that of coal gangue was measured on the basis of the National Standard of PRC (GB/T 27974-2011). The tested results are displayed in Table 1. The phase analysis of the raw materials is presented in Fig. 1.

Table 1. Chemical compositions of the raw materials (wt.\%)

\begin{tabular}{|c|c|c|c|c|c|c|}
\hline & $\mathrm{Al}_{2} \mathrm{O}_{3}$ & $\mathrm{SiO}_{2}$ & $\mathrm{Fe}_{2} \mathrm{O}_{3}$ & $\mathrm{TiO}_{2}$ & $\mathrm{CaO}$ & L.O.I \\
\hline $\begin{array}{c}\text { Burnt } \\
\text { flint clay }\end{array}$ & 45.6 & 37.8 & 1.13 & 2.6 & 0.47 & 12.4 \\
\hline $\begin{array}{c}\text { Coal } \\
\text { gangue }\end{array}$ & 36.29 & 45.75 & 3.29 & 1.02 & 0.32 & 13.33 \\
\hline
\end{tabular}

The proppant was prepared by pelleting, drying, screening and sintering, namely solid state sintering method. The weight ratio of coal gangue with respect to the calcined flint clay was 1 to 4 . First, the raw materials were mixed homogeneously in a strong mixing machine (R02, Eirich Co. Ltd, Germany) followed by formation of spherical green bodies with the addition of water. Second, after drying at $100{ }^{\circ} \mathrm{C}$ for $2 \mathrm{~h}$ in a drying box (DH-1012BS, Tianjin central experiment Furnace Co. Ltd, China), the green proppant was passed through a set of sieves of 20/40 meshes (aperture size of $0.85-0.43 \mathrm{~mm}$ ). Then the $20 / 40$ mesh proppant particles were placed in a cylindrical corundum crucible and sintered in a high temperature boxtype sintering furnace (KBF1700, Nanjing Bo Yun Tong Instrument Technology Co. Ltd, China) at different temperatures $\left(1250{ }^{\circ} \mathrm{C}, 1300{ }^{\circ} \mathrm{C}, 1350{ }^{\circ} \mathrm{C}, 1400{ }^{\circ} \mathrm{C}\right.$ and $1450{ }^{\circ} \mathrm{C}$, respectively) in air for $2 \mathrm{~h}$ at a heating rate of $5{ }^{\circ} \mathrm{C} / \mathrm{min}$. Finally, the proppant was cooled at a cooling rate of $5{ }^{\circ} \mathrm{C} / \mathrm{min}$ by furnace cooling. The cooled ceramic proppant was passed through the sieves of 20/40 meshes.

The phase compositions of the ceramic proppant were identified by powder X-ray diffraction (XRD, X'Pert PRO; Philips Co. Ltd, Holland) utilizing $\mathrm{Ni}$ filtered $\mathrm{Cu} \mathrm{K \alpha}$ radiation with operating voltage of $40 \mathrm{kV}$, scanning range of $20^{\circ}-80^{\circ}$, scanning speed of $20^{\circ} / \mathrm{min}$ and scanning step $0.02^{\circ}$. The microstructures of the sample were examined by a field emission scanning electron microscope (FESEM, S-4800; Hitachi, Japan) with operating voltage of $10 \mathrm{kV}$ and magnification of ten thousand times.

Bulk density and apparent density of the ceramic proppant were measured by a density bottle. First, weigh the $25 \mathrm{~mL}$ density bottle. Then the proppant were loaded into the density bottle until the $25 \mathrm{~mL}$ scale. Do not shake and weigh the mass. Repeat three times to take the average. The bulk density was the net weight of the proppant.

The apparent density was calculated as follows. First, fill the bottle with water and weigh it, and calculate the volume of the water $\left(\mathrm{V}_{1}\right)$. Second, pour out the water from the bottle and dry it. Add a certain amount of proppant into the bottle and weigh. Then fill the bottle with water, remove the bubbles, and continue to fill water and weigh. The volume of the proppant can be calculated by $\mathrm{V}_{1}$ minus the volume of water in the bottle with the proppant. The apparent density was calculated by dividing the mass of the proppant by the volume of the proppant. Repeat three times to take the average.

According to the Chinese Petroleum and Gas Industry Standard (SY/T5108-2014), the breakage ratio is calculated by the formula:

$\eta=\omega_{\mathrm{c}} / \omega_{0} \times 100 \%$,

where $\omega_{c}$ and $\omega_{0}$ are respectively the weight of crushed specimen after and before testing. Breakage ratio was tested under $35 \mathrm{MPa}$ and $52 \mathrm{MPa}$ closed pressure.

\section{RESULTS AND DISCUSSION}

The XRD patterns of the raw materials (calcined flint clay and coal gangue) are shown in Fig. 1. From Fig. 1 a, the main phase of calcined flint clay is donbassite, kaolinite, $\mathrm{CaAl}_{8} \mathrm{Fe}_{4} \mathrm{O}_{19}$ and $\mathrm{Ca}-\mathrm{Al}-\mathrm{Si}-\mathrm{O}$, while it can be found in Fig. 1 bthat coal gangue mainly contains quartz, kaolinite, muscovite and dolomite.

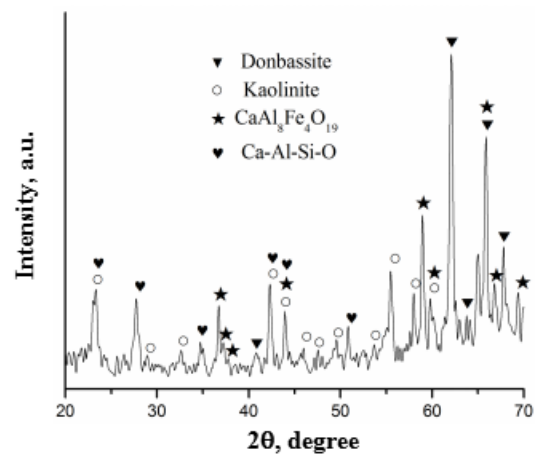

a

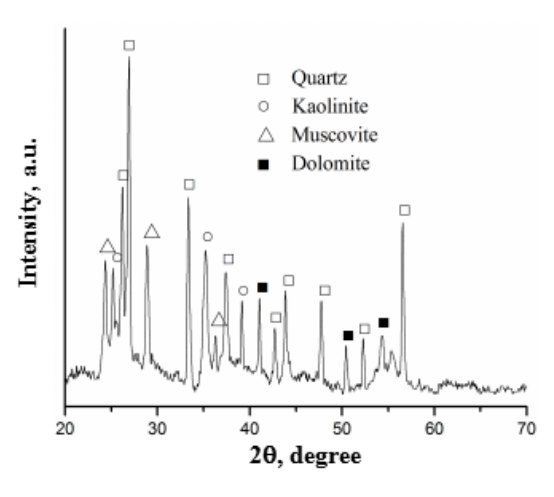

b

Fig. 1. XRD patterns of the raw materials: a-calcined flint clay; $\mathrm{b}$-coal gangue 
The XRD patterns of the ceramic proppant sintered at $1250{ }^{\circ} \mathrm{C}-1450{ }^{\circ} \mathrm{C}$ for $2 \mathrm{~h}$ are presented in Fig. 2. It can be seen that the main crystalline phases of the ceramic proppant are mullite (JCPDS: 15-0776) and cristobalite (JCPDS: 27-0605). Also planes and d-spacings of the mullite crystal are listed in Table 2 . The two diffraction peaks of $2 \theta$ at $21.604^{\circ}$ and $35.626^{\circ}$ in Fig. 2 correspond to cristobalite planes (111) and (220) with d-spacings of $4.1100 \mathrm{~nm}$ and $2.5180 \mathrm{~nm}$, respectively. Mullite results from the reaction of $\mathrm{Al}_{2} \mathrm{O}_{3}$ and $\mathrm{SiO}_{2}$, and cristobalite is formed from the transformation of $\mathrm{SiO}_{2}$. From the patterns, when the sample is sintered at $1250{ }^{\circ} \mathrm{C}$, the diffraction peaks of mullite phase are obvious and sharp, which indicates solid phase reaction at low temperature has proceeded. With the increase of sintering temperature, the diffraction peaks of mullite phase gradually become stronger. This declares the formation reaction of mullite is relatively complete. However, the diffraction peak intensity of cristobalite phase apparently decreases with the rise of sintering temperature. The diffraction peak intensity of cristobalite phase is the minimum when the ceramic proppant is sintered at $1400{ }^{\circ} \mathrm{C}$. Subsequently, the diffraction peak intensity of cristobalite phase increases again, and reaches the maximum at $1450{ }^{\circ} \mathrm{C}$. This indicates that the solid phase reaction has been carried out with the increase of sintering temperature.

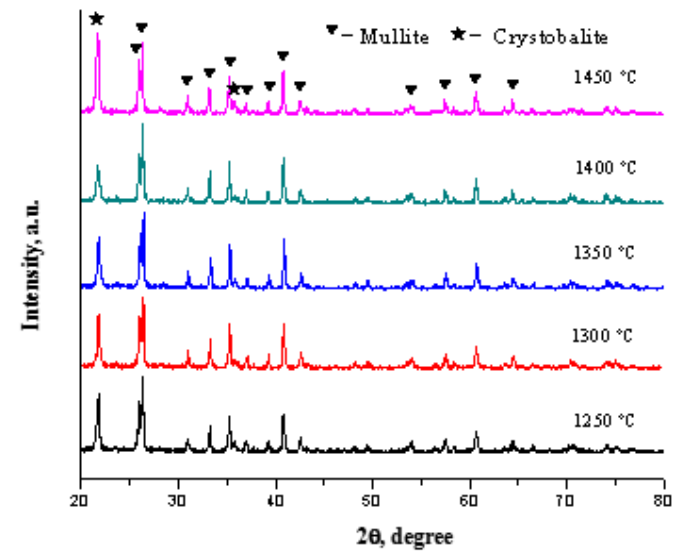

Fig. 2. XRD patterns of the ceramic proppant sintered at different temperatures

Table 2. Planes and d-spacings of the mullite crystal

\begin{tabular}{|c|c|c|c|c|c|}
\hline $\begin{array}{c}2 \theta, \\
\text { degree }\end{array}$ & (h k 1) & $\begin{array}{c}\mathrm{d}- \\
\text { spacing, } \\
\mathrm{nm}\end{array}$ & $\begin{array}{c}2 \theta, \\
\text { degree }\end{array}$ & (h k l) & $\begin{array}{c}\mathrm{d}- \\
\text { spacing, } \\
\mathrm{nm}\end{array}$ \\
\hline 25.971 & $\left(\begin{array}{lll}1 & 2 & 0\end{array}\right)$ & 3.4280 & 40.874 & $\left(\begin{array}{lll}1 & 2 & 1\end{array}\right)$ & 2.2060 \\
\hline 26.267 & $\left(\begin{array}{lll}2 & 1 & 0\end{array}\right)$ & 3.3900 & 42.590 & 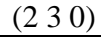 & 2.1210 \\
\hline 30.960 & $\left(\begin{array}{lll}0 & 0 & 1\end{array}\right)$ & 2.8860 & 53.883 & $\left(\begin{array}{lll}3 & 2 & 1\end{array}\right)$ & 1.7001 \\
\hline 33.228 & $\left(\begin{array}{lll}2 & 2 & 0\end{array}\right)$ & 2.6940 & 57.561 & $\left(\begin{array}{llll}0 & 4 & 1\end{array}\right)$ & 1.5999 \\
\hline 35.278 & $\left(\begin{array}{lll}1 & 1 & 1\end{array}\right)$ & 2.5420 & 60.711 & $\left(\begin{array}{lll}3 & 3 & 1\end{array}\right)$ & 1.5242 \\
\hline 36.993 & $\left(\begin{array}{lll}1 & 3 & 0\end{array}\right)$ & 2.4280 & 64.571 & $\left(\begin{array}{lll}0 & 0 & 2\end{array}\right)$ & 1.4421 \\
\hline 39.276 & $\left(\begin{array}{lll}2 & 0 & 1\end{array}\right)$ & 2.2920 & & & \\
\hline
\end{tabular}

Fig. 3 presents SEM images of the ceramic proppant sintered at different temperatures. From Fig. 3 a there exist more granular particles, which represent mullite and cristobalite crystals. This is because the crystal is not fully grown up at the lower sintering temperature. In addition, there are some very short rod-like mullite crystals with the diameter of about $300 \mathrm{~nm}$ and the length of about $1 \mu \mathrm{m}$, and big pores with the diameter of $1.5 \mu \mathrm{m}$ in the structure. These pores are connected and belong to open pores. When the ceramic proppant is sintered at $1300{ }^{\circ} \mathrm{C}$ (Fig. $3 \mathrm{~b}$ ), short rod-like mullite crystals begin to develop, and big pores with the diameter of about $1 \mu \mathrm{m}$ still exist. The ceramic proppant obtained at $1350{ }^{\circ} \mathrm{C}$ show more rod-like mullite grains (Fig. $3 \mathrm{c}$ ), and granular cristobalite grains disperse in mullite grains. Big pores disappear and the structure is compact. When the sintering temperature is up to $1400{ }^{\circ} \mathrm{C}$ (Fig. $3 \mathrm{~d}$ ), the rod-like mullite grains obviously grow up. The diameter is between $200 \mathrm{~nm}$ and $400 \mathrm{~nm}$, and the length is in the range of $500 \mathrm{~nm}$ and $3 \mu \mathrm{m}$. There is a closed pore with the diameter of about $1.5 \mu \mathrm{m}$ in the structure. In addition, the boundaries between the rod-like mullite grains begin to become obscure, which is mainly due to the glass phase generated at high temperature. Furthermore, several granular cristobalite particles are scattered around the mullite phases. In Fig. 3 e, the more glass phase generated at high temperature make the mullite and cristobalite grains compactly stick together. In comparison, the ceramic proppant sintered above $1400{ }^{\circ} \mathrm{C}$ possess more compact structure than those sintered at below $1400{ }^{\circ} \mathrm{C}$, which could be attributed to the excess glass phase.
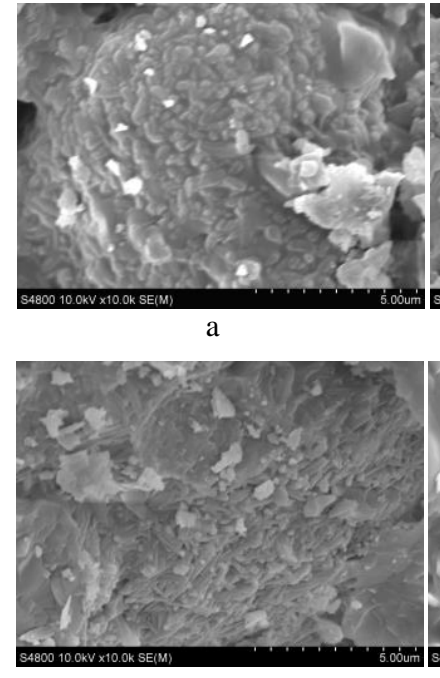

$\mathrm{c}$

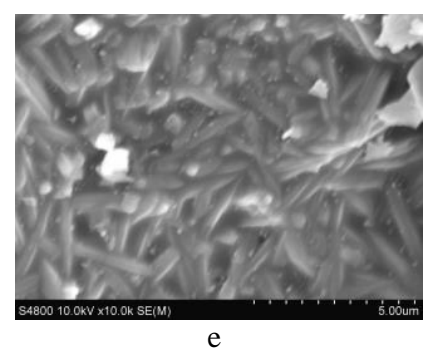

Fig. 3. SEM images of the ceramic proppant sintered at: $\mathrm{a}-1250{ }^{\circ} \mathrm{C} ; \mathrm{b}-1300{ }^{\circ} \mathrm{C} ; \mathrm{c}-1350{ }^{\circ} \mathrm{C} ; \mathrm{d}-1400{ }^{\circ} \mathrm{C}$;

Bulk density and apparent density of the prepared ceramic proppant are shown in Fig. 4. It is obvious that the both densities present an increasing trend with the increase of sintering temperature. However, bulk density and apparent density of the ceramic proppant decrease slowly when the sintering temperature is up to $1400{ }^{\circ} \mathrm{C}$. It is 
known from the above SEM results that there are many pores in the microstructure of the ceramic proppant sintered at lower temperature. Therefore, bulk density and apparent density are lower at low temperature. Subsequently, the structures of the ceramic proppant become compact as the sintering temperature rises, which can make the density increase. When the sintering temperature rises to $1400{ }^{\circ} \mathrm{C}$, the both densities reach the maximum value. This can be attributed to glass phase generated with increasing temperature. The increase of sintering temperature accelerates the reaction rate, which is beneficial to the exclusion of pores and the shrinkage of volume, thereby promoting the densification of the ceramic proppant. Bulk density and apparent density of the prepared ceramic proppant is respectively $1.27 \mathrm{~g} / \mathrm{cm}^{3}$ and $2.79 \mathrm{~g} / \mathrm{cm}^{3}$ when sintering temperature is up to $1400{ }^{\circ} \mathrm{C}$, which conform to the requirements of low-density ceramic proppant. Furthermore, bulk density of the ceramic proppant sintered at $1450{ }^{\circ} \mathrm{C}$ is almost unchanged, while apparent density slightly decreases.

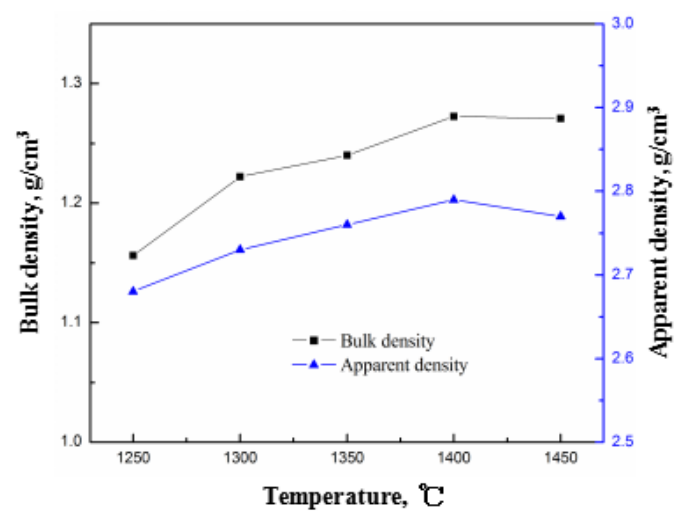

Fig. 4. Bulk density and apparent density of the ceramic proppant sintered at different temperatures

Fig. 5 are breakage ratio of the ceramic proppant sintered at different temperatures under $35 \mathrm{MPa}$ and $52 \mathrm{MPa}$ closed pressure. As is seen in Fig. 5, breakage ratios of the proppant first decrease and then increase with the increase of sintering temperature. Breakage ratioes of the ceramic proppant under $35 \mathrm{MPa}$ and $52 \mathrm{MPa}$ are the minimum value as the sintering temperature is up to $1400{ }^{\circ} \mathrm{C}$, respectively $3.27 \%$ and $8.36 \%$, which meet China industrial standard requirements SY/T 5108-2014. This is ascribed to the high compactness of ceramic proppant as mentioned above. With the elevation of sintering temperature, more mullite grains formed can make the strength of ceramic proppant increase, because mullite plays a toughening role in the structure [15]. But above all, the glass phase resulted at high temperature can perform the bonding effect on the crystalline grains. The furhter increase of sintering temperature make the breakage ratios of the proppant slightly decrease. This is consistent with the results of the above. However, it is the most important that the addition of solid waste coal gangue greatly reduces the preparation cost of ceramic proppant.

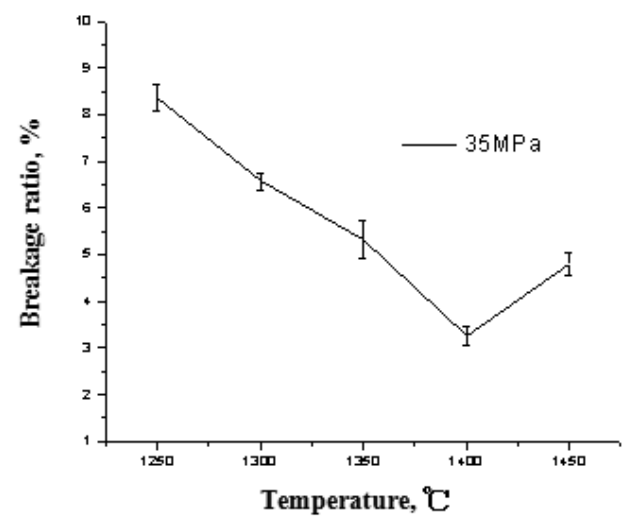

a

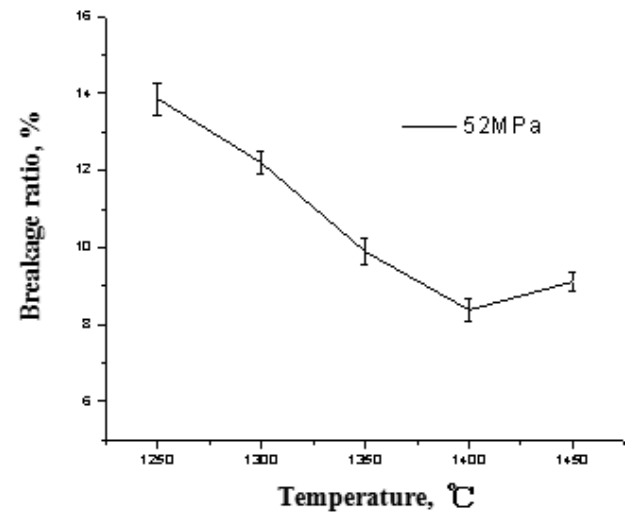

b

Fig. 5. Breakage ratio of the ceramic proppant under: a-35 $\mathrm{MPa}$ pressure; $b-52 \mathrm{MPa}$ pressure

\section{CONCLUSIONS}

Low-density ceramic proppant was successfully prepared from flint clay and solid waste coal gangue. The prepared ceramic proppant is mainly composed of rod-like mullite and granular cristobalite. Compared with the proppant prepared from bauxite, the proppant prepared from calcined flint clay and solid waste coal gangue shows the lower density. Bulk density and apparent density of the proppant sintered at $1400{ }^{\circ} \mathrm{C}$ is respectively $1.27 \mathrm{~g} / \mathrm{cm}^{3}$ and $2.79 \mathrm{~g} / \mathrm{cm}^{3}$, and the lowest breakage ratio under $35 \mathrm{MPa}$ and $52 \mathrm{MPa}$ closed pressure are respectively $3.27 \%$ and $8.36 \%$. The low-density ceramic proppant meets the requirements of the ideal fracturing materials. In addition, the addition of coal gangue greatly reduces the preparation cost of ceramic proppant, meanwhile develops a new way of solid waste recycling. Therefore, it is feasible to prepare the ceramic proppant using flint clay and coal gangue. The ceramic proppant will become desired candidate for fracturing proppant in future applications.

\section{Acknowledgments}

This work was supported by the Scientific and Technological Innovation Programs of Higher Education Institutions in Shanxi (2016-59), Talents Training Project of Shanxi Graduate Joint Training Base (2017JD33), Shanxi Province Science Foundation (201601D102019) and Fund for Shanxi Key Subjects Construction. 


\section{REFERENCES}

1. Hao, J.Y., Ma, H.Q., Feng, X., Gao, Y.F., Wang, K.Y., Tian, Y.M., Chai, Y.S. Microstructure and Fracture Mechanism of Low Density Ceramic Proppants Materials Letters 213 2018: pp. 92-94. https://doi.org/10.1016/j.matlet.2017.11.021

2. Ma, X.X., Tian, Y.M., Zhou, Y., Wang, K.Y., Chai, Y.S., Li, Z.G. Sintering Temperature Dependence of Low-cost, Low-density Ceramic Proppant with High Breakage Resistance Materials Letters 180 2016: pp. $127-129$. https://doi.org/10.1016/j.matlet.2016.04.080

3. Liang, F., Sayed, M., Al-Muntasheri, G.A., Chang, F.F., Li, L.M. A Comprehensive Review on Proppant Technologies Petroleum 2 (1) 2016: pp. 26-39. https://doi.org/10.1016/j.petlm.2015.11.001

4. Wu, T.T., Zhou, J., Wu, B.L. Effect of $\mathrm{TiO}_{2}$ Content on the Acid Resistance of a Ceramic Proppant Corrosion Science 98 2015: pp. 716-724. https://doi.org/10.1016/j.corsci.2015.06.012

5. Liu, Z.L., Zhao, J.Z., Li, Y.M., Zeng, Z.H., Mao, J.C., Peng, Y., He, Y. Low-Temperature Sintering of BauxiteBased Fracturing Proppants Containing $\mathrm{CaO}$ and $\mathrm{MnO}_{2}$ Additives Materials Letters 171 2016: pp. 300-303. https://doi.org/10.1016/j.matlet.2016.02.090

6. Hao, J.Y., Ma, H.Q., Feng, X., Gao, Y.F., Wang, K.Y., Tian, Y.M. Low-temperature sintering of ceramic proppants by adding solid wastes International Journal of Applied Ceramic Technology 15 2018: pp. 563-568. https://doi.org/10.1111/ijac.12818

7. Zhao, J.Z., Liu, Z.L., Li, Y.M. Preparation and Characterization of Low-Density Mullite-Based Ceramic Proppant by a Dynamic Sintering Method Materials Letters 152 2015: pp. 72-75. https://doi.org/10.1016/j.matlet.2015.03.060

8. Palisch, T., Duenckel, R., Wilson, B. New Technology Yields Ultrahigh-Strength Proppant. SPE Hydraulic Fracturing Technology Conference. Texas, USA,

2015: pp. $76-81$.

https://doi.org/10.2118/168631-PA
9. Qian, T.T., Li, J.H. Synthesis of Na-A Zeolite from Coal Gangue with the in-Situ Crystallization Technique Advanced Powder Technology 26 (1) 2015: pp. $98-104$. https://doi.org/10.1016/j.apt.2014.08.010

10. Liu, H.B., Liu, Z.L. Recycling Utilization Patterns of Coal Mining Waste in China Resources, Conservation and Recycling 54 (12) 2010: pp. 1331-1340. https://doi.org/10.1016/j.resconrec.2010.05.005

11. Guo, X., Ren, J., Xie, C.J., Lin, J.Y., Li, Z. A Comparison Study on the Deoxygenation of Coal Mine Methane over Coal Gangue and Coke under Microwave Heating Conditions Energy Conversion and Management 100 2015: pp. $45-55$. https://doi.org/10.1016/j.enconman.2015.04.079

12. Lv, Q.K., Dong, X.F., Zhu, Z.W., Dong, Y.C. Environment-oriented Low-cost Porous Mullite Ceramic Membrane Supports Fabricated from Coal Gangue and Bauxite Journal of Hazardous Materials 273 2014: pp. $136-145$ https://doi.org/10.1016/j.jhazmat.2014.03.026

13. Ji, H.P., Fang, M.H., Huang, Z.H., Chen, K., Li, W.J., Liu, Y.G. Phase Transformation of Coal Gangue by Aluminothermic Reduction Nitridation: Influence of Sintering Temperature and Aluminum Content Applied Clay Science $101 \quad$ 2014: pp. 94-99. https://doi.org/10.1016/j.clay.2014.07.023

14. Ji, H.P., Fang, M.H., Huang, Z.H., Chen, K., Xu, Y.G., Liu, Y.G., Huang, J.T. Effect of $\mathrm{La}_{2} \mathrm{O}_{3}$ Additives on the Strength and Microstructure of Mullite Ceramics Obtained from Coal Gangue and $\gamma-\mathrm{Al}_{2} \mathrm{O}_{3} \quad$ Ceramics International 39 (6) 2013: pp. 6841-6846. https://doi.org/10.1016/j.ceramint.2013.02.016

15. Zhao, P.F., Tian, Y.M., Liu, A.P., Kong, X.C., Chai, Y.S., Li, Z.G., Bai, P.B. Preparation and Properties of a New Medium-density and High-strength Ceramic Proppant China's Refractories 24 (2) 2015: pp. 36-41. https://doi.org/10.3969/j.issn.1004-4493.2015.02.008 